\title{
LA LITERATURA INTERRUMPIDA: HACIA UN CONCEPTO FRAGMENTARIO Y PORTÁTIL DE LA NARRATIVA BREVE ESPAÑOLA EN EL SIGLO XXI
}

\author{
Adolfo R. Posada \\ Universitatea de Vest din Timişoara \\ adolfo.rodriguez.posada@gmail.com
}

\begin{abstract}
Resumen: No han dudado en señalar los críticos literarios más destacados en el estudio de la literatura mutante española la fragmentación, la discontinuidad o la brevedad como rasgos esenciales de la escritura del siglo XXI. Pero más allá de las propuestas neovanguardistas de Agustín Fernández Mallo, Vicente Luis Mora, Manuel Vilas y Juan Francisco Ferré, o en su defecto al margen de la microficción española y la tuiteratura, rara vez se ha explorado si fundamentos como el fragmentarismo o la hibridación de géneros son recurrentes asimismo en aquellos autores y autoras españoles cuyas producciones, pese a ser fruto del espíritu postliterario del nuevo siglo, no acaban de encajar con los planteamientos teóricos afterpop y pangeicos. Así pues, tomando como referente Paraíso Alto de Julio José Ordovás, trataremos de desmenuzar los principales rasgos postliterarios que presenta la obra del escritor aragonés para aproximarnos a un concepto fragmentario y portátil de la narrativa breve en el siglo XXI, formalizado en un discurso fragmentario y discontinuo, una estructura y un desarrollo minimalista, además de una forma literaria que destaca por su portabilidad, al amoldarse la obra a distintos géneros.
\end{abstract}

Palabras clave: fragmentarismo, neorruralismo, postliteratura, narrativa mutante, literatura española del siglo XXI

\section{THE INTERRUPTED LITERATURE: TOWARDS A FRAGMENTARY AND PORTABLE CONCEPT OF THE SPANISH SHORT FICTION IN THE 21ST CENTURY}

\begin{abstract}
The most outstanding literary critics in the study of Spanish mutant literature have not hesitated to point out fragmentation, discontinuity or brevity as essential features of the $21^{\text {st }}$ century writing. But beyond the neo-avant-garde works by Agustín Fernández Mallo, Vicente Luis Mora, Manuel Vilas and Juan Francisco Ferré, or apart from the Spanish microfiction and the Twitterature, there have been no researches on whether poetic principles such as fragmentation or genre hybridization are also recurrent in those Spanish authors whose productions do not fit with the theoretical approaches on afterpop and pangeic literature, despite being considered post-literary works of the new century. So, taking into account Paraíso Alto by Julio José Ordovás as paradigm, we will try to analyse thoroughly the main post-literary features which define the Ordovás' literary work to approach a fragmentary and portable concept of the short fiction in the $21^{\text {st }}$ century, in terms of a fragmentary and discontinuous discourse, a minimalist structure and development as narrative, in addition to a literary form that stands out for its portability, by adapting itself to different genres.
\end{abstract}


Keywords: fragmentarism, neoruralism, postliterature, mutant narrative, $21^{\text {st }}$ century Spanish literature

Nota: Este artículo se ha realizado en el marco de las actividades del Proyecto de Investigación "Fractales. Estrategias para la fragmentación en la narrativa española del siglo XXI” (PID2019-104215GB-I00), financiado por el Ministerio de Ciencia e Innovación.

DOI: https://doi.org/10.24029/lejana.2020.13.442

Recibido: el 2 de noviembre de 2018

Aceptado: el 1 de marzo de 2019

Publicado: el 19 de febrero de 2020 
La narrativa de los nuevos autores españoles muestra una profunda resistencia a definirse por las rígidas convenciones de la teoría literaria. Buena parte de culpa la tiene su carácter fragmentario, en la doble acepción del término: tanto en el sentido de lo fragmentado como de lo inacabado. ${ }^{1}$ Pero los experimentos narrativos que vienen teniendo lugar en el seno de la literatura española desde hace dos décadas parecen asimismo inclinados hacia la portabilidad: ${ }^{2}$ esto es, la versatilidad característica de las nuevas obras a la hora de adaptarse a diferentes géneros gracias a la hibridación de discursos y formas.

Esta dimensión portátil de la escritura en el siglo XXI - ya sea en virtud de su naturaleza compacta, ya sea por su oscilación entre los géneros-, sumado a su carácter fragmentario, bien puede ser la causa de su manifiesta incomprensión. Me explico: los reproches dirigidos hacia la literatura influenciada o sometida al auge de las nuevas tecnologías, y en consecuencia el constante cuestionamiento de su calidad literaria, certifican la esperable caducidad de los fundamentos poéticos estilísticos y formalistas - por cuanto son incapaces de afrontar ya el examen de los nuevos planteamientos literarios sin malograrlos-; ${ }^{3}$ así como la necesidad de una renovación de los puntos de vista de la crítica en función de las nuevas mentalidades alcanzadas con el cambio de época.

Lejos quedan ya los días en que la literatura era el principal referente cultural de la sociedad. La hegemonía de la imagen y la consagración de los medios audiovisuales como principales vehículos de comunicación han acabado por eclipsar más de dos siglos de esplendor de la novela. No tiene ningún sentido, por lo tanto, seguir dándole la espalda a los hechos, negando así el papel secundario reservado para la literatura en el siglo XXI. La realidad es que esta misma se ha visto en la obligación de mutar en consonancia con los nuevos tiempos y por ello es necesario, guste o no, pensar en la escritura en unos términos teóricos más flexibles y abiertos —líquidos - en comparación con aquellos que han jalonado la teoría literaria en la modernidad.

Ahora bien, no es la primera vez que la escritura como expresión artística se enfrenta a un desafío similar, pues no olvidemos que hace justamente un siglo la aparición del cine motivó la revolución modernista en la búsqueda de nuevos derroteros para el milenario arte verbal. Lo cierto es que actualmente la literatura cuenta con numerosos y poderosísimos rivales en la lucha hegemónica de la narración. No solo el cine y las series, sino los

\footnotetext{
${ }^{1}$ La RAE (2014) recoge en el DLE la doble acepción del significado de fragmentario: 1. "Que aparece en fragmentos"; 2. "Incompleto, no acabado". Téngase en cuenta también que el carácter fragmentario de la escritura en el siglo XXI se contrapone al fundamento clásico de la unidad de la obra de arte, pilar sobre el que se asienta en gran medida la poética clásica reunida en los célebres tratados de Aristóteles y Horacio.

${ }^{2}$ El término de portabilidad procede del mundo tecnológico. Al igual que acontece con el software, cuanto mayor sea la portabilidad de una obra literaria, es decir, cuanto más híbrida y portátil sea, menor será su dependencia con respecto al género. La portabilidad es, por lo tanto, una consecuencia natural de la hibridación de los géneros, las formas y los discursos. No obstante, el concepto de portátil, a semejanza de lo fragmentario, puede entenderse en un doble sentido: como movible y transportable; o como compacto y reducido. Esta última acepción es de máximo interés para el caso de la novela corta, sobre todo cuando se enmarca en la poética portátil de Vila-Matas (2006).

${ }^{3}$ Se le puede reprochar a los críticos hispánicos que mayor resistencia han mostrado al mutacionismo que hayan antepuesto más de una vez en sus trabajos la teoría literaria al objeto de conocimiento - los propios textoslimitando su verdadera dimensión, a fin de que encaje y no desborde el molde epistemológico dado. Este procedimiento, habitual en la crítica en nuestros días, acaba por distorsionar la naturaleza diferencial de las nuevas narrativas al intentar ajustarlas a los modelos convencionales - la reducción de toda narrativa al paradigma novelesco, por ejemplo-, según un concepto canónico y académico de la literatura.
} 
videojuegos como formas narrativas casan mucho mejor tanto con el paso acelerado del tiempo que nos ha tocado vivir como con el imagocentrismo de nuestra sociedad. ${ }^{4}$

Por este mismo motivo parece lógico que el propio arte verbal, en su intento de distanciarse de sus competidores, ofrezca modelos narrativos disruptivos que favorezcan un horizonte de expectativas novedoso que minimice su pérdida de protagonismo. Frente a la natural obsolescencia a la que parece condenada la literatura como expresión cultural, resulta inevitable que los nuevos creadores pretendan renovar el arte de la escritura en vista de la exploración de conceptos poéticos y planteamientos narrativos acordes al mundo tecnológico que nos rodea. Si bien la obsolescencia de la literatura parece inevitable y quizás no le corresponda más que compartir tarde o temprano idéntico destino que el ballet o el teatro -manifestaciones artísticas reducidas hoy a una mínima expresión de lo que fueron en el siglo XIX-, se trata de sumar la escritura a la revolución tecnológica, ponerla en cierto modo a su servicio o al menos dejarse influir por sus innovaciones, a imitación de los artistas vanguardistas de última generación, en vez de obcecarse en defender una posición cultural perdida sin acabar de asumir la realidad de la derrota.

De ahí que se haya dicho que la condición de las nuevas propuestas literarias en el ámbito español sea primordialmente mutante, por cuanto los genes literarios están siendo alterados por la anomalía que ha supuesto el impacto tecnológico en la transformación cultural producida en las primeras décadas del siglo XXI. El concepto pangeico de la escritura desarrollado por Vicente Luis Mora (2012), bajo el cual se concibe la página como una pantalla (pantpágina) y la escritura, por ende, como un diseño tecnográfico, es una muestra representativa de dicha proposición. Lo mismo puede alegarse de la estética afterpop como concepción mediática de la literatura, según la tesis de Fernández Porta (2010); o bien el modo en que buena parte de los escritores españoles del siglo XXI abogan por el mutacionismo de las formas, la hibridación de los géneros, y una mayor portabilidad y fragmentarismo de la narrativa frente a su modelo estándar convencional: la novela.

Quizás por tal motivo no quepa ya hablar de literatura, ${ }^{5}$ sino de una nueva concepción del arte verbal, determinada por directrices poéticas diferentes a las acostumbradas. Experimentos narrativos como Proyecto Nocilla de Agustín Fernández Mallo (2013) o la serie Circular de Mora (2007) dinamitan los pilares que hasta ahora han sostenido la escritura como arte poético. Las novelas mutantes de Manuel Vilas, Juan Francisco Ferré o Blanca Riestra tampoco acaban de encajar con los procedimientos reconocibles del género, circunstancia que impide muchas veces incardinar a tales autores en las coordenadas de la tradición novelística española, lo cual conduce casi siempre a su incomprensión y su ostracismo, cuando no directamente a su condena.

\footnotetext{
${ }^{4}$ El concepto de imagocentrismo procede de las reflexiones de De la Flor en el marco de las directrices estéticas y culturales del nuevo siglo: "Este antiguo enfrentamiento entre sistemas de representación sobre el que han sido vertidos ríos de tinta alcanza hoy, entre nosotros, un momento verdaderamente climático y especial, no sólo porque parece que la «civilización de la imagen», $\mathrm{y}$, en general, el proceso que ha podido ser conocido como «imagocentrismo» (o, también, si lo que se acentúa es la otra polaridad del hecho visual: el «ocularcentrismo») avanza sobre sí mismo, descubriendo las fronteras insospechadas de lo digital, lo holográfico, lo virtual, generando así una «democracia»" (2007: 71).

${ }_{5}^{5}$ Desde principios de siglo, la crítica argentina lleva postulando el teórico fin de la literatura a través de figuras como Speranza (2000), Ludmer (2006) o Topuzián (2013).
} 
Cabría preguntarse por eso mismo, yendo todavía más lejos y con la idea en mente de la inevitable obsolescencia de la literatura, si criterios poéticos clásicos como verosimilitud, estilo, decoro o género siguen siendo pertinentes a la hora de comprender, enjuiciar y criticar en su justa medida la escritura de nuestro tiempo. Criterios que al ser aplicados a la mayoría de novelas actuales dificultan su comprensión al anteponer la teoría a la praxis, la poética convencional y normativa a la escritura creativa y libre de trabas. Una escritura ya no definida en términos de una poética de raigambre aristotélica y de herencia formalista y estilística, sino según un modelo tecnográfico donde los conceptos de simulacro, portabilidad, fragmentación, hibridación, conectividad o diseminación vienen a sustituir a los antiguos criterios ontológicos.

Tal vez los genes de la literatura hayan mutado de suerte que estemos asistiendo, he aquí mi hipótesis, a un cambio de paradigma literario como el que tuvo lugar en el Renacimiento con motivo de la invención de la imprenta y el posterior inicio de la Galaxia Gutenberg. De igual forma que la Rota Virgilii y las unidades dramáticas de inspiración aristotélica dejaron de definir la poesía en su sentido clásico a partir del éxito de las novelas de Cervantes y la comedia nueva de Lope de Vega, forzando un cambio en el espectro del arte verbal desde lo poético a lo literario, hoy día es posible que estemos asistiendo a la interrupción de la literatura en su concepción belletrística moderna y al nacimiento de su nuevo concepto como escritura posthumanista. ${ }^{6}$

Pero no se piense que se limita esta revolución (post)literaria silenciosa a la obra de los escritores deliberadamente mutantes, sino asimismo puede perfectamente extenderse a aquellos autores españoles cuyas producciones, pese a no situarse en el ámbito teórico ni afterpop ni pangeico, presentan por igual el fragmentarismo, la portabilidad o la hibridación de géneros como rasgos esenciales. Narrativas diferenciales -en el sentido derridiano del término- cuya índole mutacionista, como digo, responde a criterios muy distintos de los habitualmente empleados en el análisis y juicio de la literatura: verosimilitud y coherencia en la construcción, estilo y expresividad, decoro y pertinencia con el género.

Así pues, artefactos postliterarios como Menos joven de Rubén Martín Giráldez (2012) o Los combatientes de Cristina Morales (2013), que aun pudiéndose considerar novelas cortas que se ajustan a un modelo de narrativa breve en apariencia tradicional, no terminan de encuadrarse en el propio género: son obras cuyo carácter anfibio potencia su portabilidad, ${ }^{7}$ al hallarse, tanto por su extensión reducida como por su hibridación genérica, en las fronteras de la novela corta, el monólogo teatral, el opúsculo, el vodevil o el diario.

Siguiendo este hilo de pensamiento, tampoco parece casual que los principales referentes del movimiento mutante en España, además de caracterizarse por un marcado fragmentarismo, sean precisamente narrativas breves y propuestas literarias por lo general portátiles. Aun cuando se observa en la literatura española actual una tendencia al realismo histérico y al maximalismo como destaca Francisca Noguerol (2013) —Providence de Ferré

\footnotetext{
${ }^{6}$ Por escritura posthumanista, entiendo aquellas formas de escritura que se producen en un contexto social en el cual, como señala Sloterdijk (2000: 28-29), los textos han dejado de ser el centro de gravedad cultural. Así pues, nos encontraríamos ante modelos sociales y culturales "decididamente post-literarios, post-epistolográficos, y en consecuencia post-humanísticos" (2000: 28).

${ }^{7}$ Hace ya una década Gómez Trueba recuperaba la noción de "literatura anfibia", acuñada por José Carlos Llop, justamente para describir "esta tendencia acusada al hibridismo genérico de la literatura actual [que] ha traído consigo el triunfo de un nuevo tipo de novela" (2007: 16).
} 
(2009), Los hemisferios de Cuenca Sandoval (2014), Brilla, mar del Edén de Andrés Ibáñez (2014) - , existe por igual una tendencia a lo micro en consonancia con los nuevos modelos aceleracionistas de recepción, el minimalismo imperante o la fractalidad favorecida por el montaje narrativo en fragmentos.

Es tan solo una hipótesis que no pretendo desarrollar aquí por falta de espacio, pero pone de relieve la complejidad de una nueva forma de concebir el arte de la escritura como así han tratado de evidenciar los principales especialistas en literatura española del siglo XXI —desde Navajas (2000) y Gullón (2004), pasando por Mora (2007b, 2008, 2012, 2015), Gómez Trueba (2007, 2009), la propia Noguerol (2013) o Ferrari Nieto (2014), hasta Calles (2011), Saum-Pascual (2012, 2018), Pantel (2012) o Ilasca (2016)—.

Lo cierto es que si existe un género donde se manifiesta esta realidad con mayor fuerza y precisión es justamente en la novela corta. Tomando como referencia el análisis de Carmen Pujante (2011: 248-264), cabe destacar que la narrativa breve como propuesta narratológica tiende por naturaleza a la experimentación, pues “como género excéntrico y a su pequeña escala, la nouvelle vendría a reproducir una contestación o un «libertinage narratif» respecto a la gran obra" (2011: 253). Desde luego, parece obligado concordar con Pujante en que la narrativa breve se vincula, especialmente a partir del posmodernismo - desde Borges hasta Vila-Matas - con la "estética de la ruptura, a menudo contra la novela" (2011: 254). Pauta que no deja de observarse entre los autores y autoras más experimentales de nuestra literatura reciente, quienes suelen decantarse por la narrativa corta en virtud de sus "rasgos excéntricos o rupturistas", según Pujante: la pronunciada brevedad, la reducción del realismo o "la tendencia a cierta circularidad, cierta desrealización y cierto anonimato caracterizador de personajes" (2011: 253).

El minimalismo narrativo, desde su forma tradicional como novela corta hasta sus desviaciones posmodernas como microficciones y tuiteratura, se asentaría sobre un concepto de la literatura portátil, tal y como fue concebida en Historia abreviada de la literatura portátil por Vila-Matas (2006), en consonancia con la tendencia aceleracionista de la sociedad de la información a mediados de los años 80 — una sociedad donde se perseguía ya la comunicación con la mayor brevedad y velocidad posible-; pero también sobre una concepción experimental de la novela como narración fragmentaria $-o$ bien transmitida a través de fragmentos que forman cohesionados un volumen compacto; o bien fracturada, en el sentido de una literatura interrumpida, inacabada, incompleta, desestructurada y desjerarquizada, esto es, rizomática-. Una narración fragmentaria donde el tiempo y el espacio se encuentran "desrealizados" o "irrealizados", dada la licuefacción del propio tiempo y espacio vivida en la posmodernidad tras la fundación de la red global, sin olvidar tampoco el protagonismo de unos personajes que desarrollan las acciones bajo el anonimato, personalidades fluctuantes o identidades nómadas.

Partiendo de las conclusiones de Pujante (2011: 257), cabría añadir que ya no solo nos encontraríamos ante un modelo heredero de la modernidad "antilineal" que ha venido determinando la novela corta en el pasado siglo XX, sino dentro de una concepción novedosa de la narración misma como discurso portátil, elíptico y fragmentado. ${ }^{8}$ Un modelo de

\footnotetext{
${ }^{8}$ Cabe recordar a este respecto que el cuento moderno, según la tesis de Piglia, es siempre "narrado de un modo elíptico y fragmentario" (2000: 106). Y por consiguiente, la narrativa breve en el mundo contemporáneo como procedimiento escritural se fundamenta en gran medida en "el arte de la elipsis" (Piglia, 2000: 109).
} 
narrativa, en suma, adecuado al acusado aceleracionismo que marca el devenir de nuestra época, y que se rige en último término, siguiendo el apunte de Pujante, por "el principio de economía propio de la brevedad del género literario en cuestión" (2011: 304). El objetivo de los escritores españoles más experimentales, consciente o inconscientemente, quizás haya consistido en distanciarse de las propuestas narrativas más comerciales —caso de los extensos bestseller o las sagas novelescas-; o quizás se hayan inclinado por la versatilidad de la narrativa breve al distanciarse su estética rupturista de las formas de narración convencionales sobre las que suelen articularse las narrativas audiovisuales -cine, series, anime, videojuegos, etc.-, promoviendo un modelo literario independiente del mercado y de la escena mainstream, y muy propicio para la experimentación, la reflexión filosófica y la exploración de la creatividad artística. En conclusión, ya no hablaríamos únicamente de brevedad (pos)modernista, sino antes bien de portabilidad y fragmentarismo de última generación.

Los artefactos mutantes, en efecto, suelen encontrar en la narrativa breve un firme aliado para desarrollar un modelo postliterario de escritura artística, propio del siglo XXI, que manifiesta claramente el influjo de las nuevas tecnologías y el impacto que lo digital está teniendo en la sociedad de nuestro tiempo. ${ }^{9}$ Una escritura portátil marcada por la narratividad y la brevedad — señas de identidad de la novela corta-, pero que, a diferencia de su versión acostumbrada, oscila al mismo tiempo como se ha dicho en la frontera de múltiples géneros -el teatro, la novela, el inventario, el poema lírico, la crónica - en correspondencia con la hibridación o mutación genológica y la dimensión pangeica de los discursos en la red. Así acontece con las propuestas narrativas mencionadas de Fernández Mallo, Mora, Ferré, Martín Giráldez o Morales, reconocidas y destacadas indudablemente por su grado de experimentación y su búsqueda incesante de una nueva expresividad. ${ }^{10}$

Pero en lo que respecta a aquellos autores españoles del siglo XXI no vinculados directamente al mutacionismo como movimiento, la afiliación a una forma de escritura portátil y fragmentaria resulta menos evidente $\mathrm{y}$, por lo tanto, se torna problemático su planteamiento a efectos de teorización y comprensión. Podría ser el caso de una nómina de escritores que incluiría entre otros a Jon Bilbao (2008), Pilar Adón (2010) o Julio José Ordovás $(2014,2017)$, pues sus narraciones ofrecen, más allá de las posturas experimentales referidas, ejemplos mucho más llamativos y menos evidentes de esta nueva concepción postliteraria del arte verbal prominente en el presente siglo. En especial, destaco aquí como paradigma la novela corta Paraíso Alto de Ordovás publicada en la editorial Anagrama en 2017. Lo interesante de esta publicación — de ahí que me haya decantado por ella, si bien podríamos aplicar lo dicho aquí a buena parte de la narrativa breve de Bilbao o Adónestriba en que, a pesar de poder considerarla una novela corta convencional —enmarcada si cabe en la llamada corriente neorruralista dentro de la actual literatura española-, comparte

\footnotetext{
${ }^{9}$ Véanse los trabajos de Calles (2011), Saum-Pascual (2012, 2018), Pantel (2012) e Ilasca (2016), centrados justamente en analizar el impacto de las nuevas tecnologías y el medio audiovisual en la literatura española reciente.

${ }^{10}$ La búsqueda de una nueva expresividad es lo que determina para Mora el experimentalismo de muchos escritores españoles actuales, si bien en su caso centra tal tendencia en el marco de su propuesta teórica: "las formas de narrativa española pangeica [...] son la mutación de una especie agonizante, en aras de una nueva expresividad: la textovisual, la que conjuga texto e imagen en lo horizontal, y una continuidad de artes, ciencias y tecnologías en su semántica vertical. Una especie de porvenir que sucede en el presente” (2008: 63).
} 
numerosos rasgos que la aproximan al modelo experimental mutante, lo cual dificulta su comprensión como nouvelle al uso e instiga, a partes iguales, tanto las críticas como los elogios que ha cosechado el autor aragonés desde la publicación de El Anticuerpo en 2014.

Sin duda, cuando nos aproximamos a Paraíso Alto todo parece indicar que nos encontramos en apariencia ante una novela corta, máxime si atendemos a su extensión - la obra abarca 136 páginas-. Toda la acción transcurre en un mismo espacio, el pueblo abandonado de Paraíso Alto, que sirve justamente de escenario para el desfile de personajes que protagonizan la sucesión de escenas y narraciones que conforman la historia.

El carácter sucesivo de la narrativa breve de Ordovás permite concebir, por otro lado, la estructura de la novela en correspondencia con el cronotopo del encuentro, en concreto de la "pequeña ciudad provinciana", según la proposición de Bajtín (1989: 398). Razón por la cual se haya distinguido en la narración de Ordovás ecos de Comala de Juan Rulfo (1998), a juzgar por la descripción fantasmagórica y espectral que el narrador nos ofrece del pueblo desolado: "Paraíso Alto está orientado únicamente al suicidio. En sus calles, barridas por la desolación, solo se oyen palabras sin vida que resuenan al rodar por el empedrado" (Ordovás, 2017). ${ }^{11}$

La singularidad macabra de Paraíso Alto pasa por su condición de espacio mortuorio. Se trata de un pueblo abandonado al que la gente acude para suicidarse. Se presenta, así pues, como el escenario del singular ars moriendi celebrado a lo largo de toda la narración fragmentada. De tal modo que se compone la novela corta de Ordovás de todos los fragmentos narrativos protagonizados por los diferentes suicidas que, auxiliados por el personaje principal, conducen sus pasos hacia la muerte. Van entrando en escena cada uno de ellos - desde desertores y ancianos fugados de residencias hasta actrices porno y titiriteros-, como si se tratase de una mascarada carnavalesca, o bien un desfile de sombras fúnebres que participa de un sacrificio nihilista como rechazo a la alienación y ansiedad que condicionan la vida en la sociedad posindustrial del siglo XXI. Son los protagonistas, en definitiva, que asisten al desahucio de un mundo sumido en una profunda crisis moral y una ausencia total de los valores humanos.

Aun cuando la peculiar ambientación de la narrativa breve de Ordovás invita a asociarla al neorruralismo literario peninsular, no deja de compartir al mismo tiempo el gusto por los espacios abandonados y ruinosos manifestado por los principales escritores mutantes: "Los habitantes de Paraíso Alto abandonaron el pueblo dejando la ropa en los armarios, los platos sobre las mesas y las llaves en las puertas" (Ordovás, 2017). Todo ello es reflejo, sin duda, de la concepción de la realidad como un desolado desierto de lo real, recurriendo a la fórmula expresiva de Slavoj Žižek (2005), participando así el autor aragonés del tópico

\footnotetext{
${ }^{11}$ Todas las citas de la novela de Julio José Ordovás pertenecen a la edición digital en formato EPUB de Paraíso Alto (Madrid, Anagrama, 2017). Dado que la paginación varía dependiendo del dispositivo que se emplee para la lectura del libro de Ordovás en su versión electrónica, y sumado a que no existe la posibilidad de referir de forma eficaz el número de párrafo, como suele ser habitual en la citación de libros electrónicos, excuso citar tanto las páginas como los párrafos de la obra. En caso de que se desee consultar la cita en su contexto y para superar la dificultad, el lector bien puede emplear el buscador interno de su dispositivo para localizar con exactitud el punto de la obra en la que se encuentra el fragmento seleccionado.
} 
reconocible dentro de la literatura española del nuevo siglo en torno al abandono de lugares y la huida de las ciudades. ${ }^{12}$

Todos los personajes y sus historias fragmentadas tienen como nexo común el personaje principal, sobre el cual se focaliza la narración y sirve como hilo conductor de los distintos fragmentos que, en su montaje final como novela portátil, componen Paraíso Alto. Puede entreverse en la figura del protagonista un trasunto de Caronte; pero también, en la propia extensión del pueblo, un espacio transcendental, ficcional, un lugar fronterizo entre el cielo y la tierra, o en su defecto, entre la tierra y el infierno. Según esta visión escatológica de la realidad humana, Ordovás invoca el espíritu apocalíptico que estila asimismo buena parte de la literatura española de principios de siglo, la cual bien podríamos encuadrar en lo que Bifo Berardi (2017) ha dado en llamar la "fenomenología del fin". Tal consistencia acerca del fin de los tiempos y la llegada del juicio final se ve constantemente reflejada en la obra de escritor aragonés: "La gruta del Charco del Agua Muerta es un lugar que invita a la oración o, al menos, al recogimiento. El agua que rezuman las paredes de piedra caliza ha pintado en ellas una especie de retablo que, dependiendo del estado anímico con que se observe, semeja una representación del juicio final o un baile de máscaras" (Ordovás, 2017).

Paraíso Alto se convierte así en una suerte de novela mortuoria que no deja de traer a la mente por otra parte el moridero imaginado por Bellatin en Salón de belleza (2000). Por medio de la falacia patética, que vertebra por igual la literatura española actual ambientada insospechadamente en espacios rurales -Intemperie de Jesús Carrasco (2013), Por si se va la luz de Lara Moreno (2013), Alabanza de Olmos (2014)—, el paisaje rural desolado como locus eremus acaba por exteriorizar, a semejanza de lo que acontecía en las novelas románticas, el universo interior de unos personajes sumidos en la desolación, la tristeza, la soledad y el ansia por alcanzar la muerte, en sintonía con el nihilismo que caracteriza a muchos de los protagonistas de las novelas hispanas de última generación -ejemplificado en el homo lubitz de Menéndez Salmón (2018)—.

La novela de Ordovás se hace portavoz, por añadidura, de otra de las principales preocupaciones que centra la atención de nuestra literatura en el momento actual: la tópica en torno a la desesperación, la angustia y la ansiedad, así como todas aquellas enfermedades psicológicas vinculadas a la sociedad posindustrial y el mundo globalizado. Un mundo globalizado y una vida acelerada que no acaba de congeniar con el microcosmos humano, frustrando la existencia de la galería de espectros que deambulan desorientados por Paraíso Alto. Una vez más el espacio se convierte aquí en una extensión o una realidad ampliada de la desolación interior de los personajes. Es el protagonista por excelencia de la novela: "no es un pueblo fantasma ni una aldea maldita, es solo un pueblo desesperado" (Ordovás, 2017).

Más que una narración, Paraíso Alto (re)presenta un retrato sucesivo de suicidas. Son historias fragmentadas que dan lugar a un conjunto narrativo portátil, incompleto e inacabado, antes que a una novela corta convencional. Como en la anterior publicación de Ordovás, $E l$ Anticuerpo, la narrativa breve del escritor aragonés no acaba de acogerse una vez más al género novelesco, a causa de su tratamiento del estilo, ya sea como consecuencia de la

\footnotetext{
${ }^{12}$ No solo en el contexto del neorruralismo es tópico el abandono de las ciudades y la huida al mundo apartado, sino asimismo es recurrente la temática en autores y autoras ajenos a dicha corriente, como es el caso de Sara Mesa en Un incendio invisible (2017). Reflejo quizás, siguiendo el pensamiento de Žižek, de la resistencia del ser humano a la ideología capitalista y al simulacro virtual de una realidad cada vez menos real y "desrealizada".
} 
influencia del lirismo en la escritura del autor, ya sea por su marcado minimalismo. ${ }^{13} \mathrm{Se}$ caracteriza la obra por su portabilidad, lo cual le permite al autor moverse entre géneros y fluctuar entre diversas categorías discursivas: la narración breve, la crónica, el poema narrativo, el opúsculo o incluso el catálogo. Al no presentar dirección alguna para su significación, no queda claro si se trata de una novela corta o un conjunto de relatos, algo que recuerda a la problemática iniciada por Aira con el experimentalismo que caracteriza su narrativa breve. ${ }^{14}$

Los diferentes segmentos narrativos correspondientes a las historias de los suicidas forman narraciones incompletas, inacabadas, interrumpidas, pero alcanzan una cohesión conjunta - he aquí uno de los pilares de la poética mutante-, al enmarcarse en el todo narrativo como estructura reticular. ${ }^{15}$ La novela no se define tanto por la narración y la brevedad, como así precisa la definición misma de la novela corta, cuanto por el carácter fragmentario y portátil reconocible en la escritura mutante española. En conclusión, no hablaríamos tanto de una simple vuelta de tuerca del género de la novela corta, cuanto de una nueva modalidad de escritura portátil y fragmentaria supeditada al peculiar contexto cultural y literario del siglo XXI.

Lo interesante de la narrativa de Ordovás es que no comulga con un fragmentarismo reticular y pangeico como el que caracteriza la escritura de Fernández Mallo o Mora, sino con una modalidad fragmentaria velada y sutil, de la que participa una nómina de autores y autoras españolas que, sin llegar a ser deliberadamente experimentales, su escritura diferencial desborda, en mayor o menor medida, el tradicional concepto de novela (corta). Prueba de ello es que no existe en Paraíso Alto ni una trama específica ni un desenlace para la historia. ${ }^{16}$ En ningún momento se resuelve el conflicto de la historia narrada, permaneciendo interrumpida en último término al prescindir, como viene siendo habitual en el cuento moderno conforme a la observación de Piglia, "[d]el final sorpresivo y la estructura cerrada" (2000: 106).

No obstante, tampoco existe un interés real por presentar una historia secreta mediante una estructura elíptica de significaciones que permita la revelación de una epifanía: únicamente nos encontramos, reformulando la tesis de Piglia, ante una historia secreta sin ni siquiera historia. Toda la narración se construye exclusivamente por lo tanto "con el

\footnotetext{
${ }^{13}$ Con respecto a esta peculiaridad estilística de Ordovás, señala justamente Javier Goñi (2018) en su reseña de Paraíso Alto, publicada en Babelia, que "sus párrafos, breves, están cuidados como si fueran versos perfectos" (en línea).

${ }^{14}$ El propio Aira (2016) declaraba abiertamente en una entrevista la naturaleza poco convencional de su narrativa antinovelesca: "De joven intenté escribir novelas que se parecieran a las novelas de verdad, porque quería ser publicado y hacer algo que los editores entendieran de qué se trataba, pero con el tiempo me fui liberando de eso y hoy día creo que escribo, como yo diría, la sombra de una novela. He ido cambiando mis definiciones, que las hago un poco para divertirme y para burlarme de los periodistas que me preguntan. Hasta hace poco definía mis libros como «cuentos de hadas dadaístas», pero ahora los defino como «juguetes literarios para adultos»" (en línea).

${ }^{15}$ Así mismo acontece con los relatos reticulares que dan vida a los proyectos narrativos mutantes de Fernández Mallo, Mora o Vilas.

${ }^{16}$ Si bien el fragmentarismo guarda relación con la narrativa fragmentada de los escritores mutantes, se aproxima aquí a la poética de lo inacabado e inconcluso que caracteriza a muchas de las narraciones románticas —desde el Anton Reiser de Moritz, pasando por el Wilhelm Meister de Goethe, hasta la Lucinde de Friedrich Schlegel一. Al igual que acontece en el final abrupto del Künstlerroman en la Alemania romántica, la novela corta de Ordovás no termina del todo, se ve interrumpida y se halla inconclusa, dando a entender que la vida prosigue en el simulacro ficcional a semejanza de lo que sucedería en la realidad. Para una ampliación de la materia, véase la interesante distinción establecida por Mora (2015) entre el fragmentarismo y el fragmentalismo.
} 
sobrentendido y con la alusión" (Piglia, 2000: 108). Tan solo hay lugar para revindicar la naturaleza líquida y fluctuante, inestable y mutante, del nuevo signo literario, en comunión con el espíritu diseminativo que Derrida contemplaba en la literatura más experimental, ante "la imposibilidad de reducir un texto como tal a sus efectos de sentido, de contenido, de tesis o de tema" (1997: 13).

Esta naturaleza fragmentaria de la escritura portátil de Ordovás encuentra su reflejo en las propias historias. Los personajes van y vienen sin acabar de quedarse. No se molestan ni siquiera por dar término a sus historias. Se ven interrumpidas y permanecen por lo tanto fragmentadas, rotas por una narración incompleta e inacabada, como así acontece con la historia del personaje del viejo aragonés: "Todo es amarillo, dijo el viejo con un susurro interrumpiendo de forma brusca el relato. Tenía razón. Todo, a nuestro alrededor, era amarillo, incluso el cielo. Después el viejo cerró los ojos y no volvió a abrir la boca ni a mover un músculo. Yo lo dejé allí, en la piedra de los sacrificios, y me fui a jugar a otra cosa" (Ordovás, 2017).

Las constantes interrupciones a las que se ven sometidas las historias narradas por los suicidas que pueblan Paraíso Alto son prueba del manifiesto fragmentarismo de la escritura de Ordovás. Pese a su aparente convencionalismo temático, un examen en profundidad de Paraíso Alto desvela que no nos encontramos ante una narración tradicional, sino ante un artefacto mutante condicionado tanto por la índole fragmentaria del arte verbal como por los diferentes denominadores comunes de la escritura portátil del siglo XXI: el simulacro narrativo frente a la verosimilitud realista; la portabilidad de las formas mutantes frente a las pautas rígidas del género; la diseminación o ambigüedad frente al sentido unívoco y la lectura unilateral; la extensión y ampliación metonímica de los espacios y objetos frente al simbolismo de la representación metafórica; o el grado cero de la escritura y el vaciado del estilo belletrístico, puro reflejo de la desolación que reina en todo momento en Paraíso Alto.

\section{Bibliografía}

\section{Obras citadas}

AIRA, César (2016): "No hago novelas, sino juguetes literarios para adultos (entrevista por Álvaro Mutus)". Revista Santiago, 25 de noviembre de 2016. Recuperado de: http://revistasantiago.cl/actualidad/cesar-aira-no-hago-novelas-sino-juguetes-literariospara-adultos/ [17/10/2018].

BERARDI, F. "BIFO" (2017): Fenomenología del fin. Sensibilidad y mutación conectiva. Buenos Aires, Caja Negra.

DE LA FLOR, Fernando R. (2007): "El impacto de los Visual Studies y la reordenación del campo de disciplinas del texto en nuestro tiempo". Hispanic Issues Online, 2: 65-80. Recuperado

de: https://cla.umn.edu/sites/cla.umn.edu/files/hiol_02_05_delaflor_el_impacto_de_los_vi sual_studies.pdf $[17 / 10 / 2018]$.

DERRIDA, Jacques (1997): La diseminación. Madrid, Fundamentos.

FERNÁNDEZ PORTA, Eloy (2010): Afterpop. La literatura de la implosión mediática. Barcelona, Anagrama. 
GÓMEZ TRUEBA, Teresa (2007): "El nuevo género de las novelas anti-género”. Letras Hispanas 4.1 (Spring 2007): 16-27.

GOÑI, Javier (2018): "Enhebrar los sueños". Babelia (El País), 22 de enero de 2018. Recuperado de https://elpais.com/cultura/2018/01/16/babelia/1516125019_548090.html [17/10/2018].

MORA, Vicente Luis (2008): "El porvenir es parte del presente. La nueva narrativa española como especies de espacios". Hofstra Hispanic Review 8/9: 48-65.

NOGUEROL JIMÉNEZ, Francisca (2013): "Barroco frío: simulacro, ciencias duras, realismo histérico y fractalidad en la última narrativa en español”. En J. M. Juárez y A. Esteban (eds.), Imágenes de la tecnología y la globalización en las narrativas hispánicas. Madrid / Frankfurt, Iberoamericana / Vervuert: 17-32. DOI: https://doi.org/10.31819/9783954871940-002

ORDOVÁS, Julio José (2014): El Anticuerpo. Barcelona, Anagrama.

PIGLIA, Ricardo (2000): “Tesis sobre el cuento”. En su libro Formas breves. Barcelona, Anagrama: 105-111.

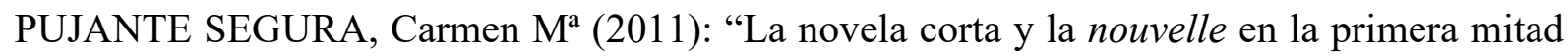
del siglo XX. Estudio crítico comparado a partir de seis autoras". Tesis doctoral, Universidad de Murcia. Recuperado de: https://www.tesisenred.net/handle/10803/51493 [17/10/2018].

REAL ACADEMIA ESPAÑOLA (2014): "Fragmentario". Diccionario de la lengua española (23. ${ }^{\text {a }}$ ed.). Recuperado de: http://dle.rae.es/srv/search?m=30\&w=fragmentario [17/10/2018].

SLOTERDIJK, Peter (2000): Normas para el parque humano. Madrid, Siruela.

VILA-MATAS, Enrique (2006): Historia de la literatura portátil. Barcelona, Anagrama.

ŽIŽEK, Slavoj (2005): Bienvenidos al desierto de lo real. Madrid, Akal.

\section{Obras mencionadas}

ADÓN, Pilar (2010): El mes más cruel. Madrid, Impedimenta.

BAJTÍN, Mijail (1989): Teoría y estética de la novela. Madrid, Taurus.

BELLATIN, Mario (2000): Salón de belleza. Barcelona, Tusquets.

BILBAO, Jon (2008): Como una historia de terror. Madrid, Salto de Página.

CALLES, Jara (2011): "Literatura de las nuevas tecnologías. Aproximación estética al modelo literario español de principios de siglo (2001-2011)". Tesis doctoral, Universidad de Salamanca. Recuperado de: http://hdl.handle.net/10366/110856 [17/10/2018]. DOI: https://doi.org/10.14201/gredos.110856

CARRASCO, Jesús (2013): Intemperie. Barcelona, Seix Barral.

CUENCA SANDOVAL, Mario (2014): Los hemisferios. Barcelona, Seix Barral.

FERNÁNDEZ MALLO, Agustín (2013): Proyecto Nocilla. Barcelona, Alfaguara.

FERRARI NIETO, Enrique (2014): Resistencias con lo digital. Madrid, Catarata.

FERRÉ, Juan Francisco (2009): Providence. Barcelona, Anagrama. 
GÓMEZ TRUEBA, Teresa (2009): "Narrativa española del 2008: explorando «nuevos» caminos para la ficción”. Siglo XXI 7: 77-97.

GULLÓN, Germán (2004): “La novela española: 1980-2003”. En A. Orejudo (coord.), En cuarentena: nuevos narradores y críticos a principios del siglo xxi. Murcia, Universidad de Murcia: 15-37.

IBÁÑEZ, Andrés (2014): Brilla, mar del Edén. Barcelona, Galaxia Gutenberg.

ILASCA, Roxana (2016): “Le réseau mutant: propositions d'une nouvelle (post)poétique narrative dans les oeuvres de Jorge Carrión, Agustín Fernández Mallo et Vicente Luis Mora”. Tesis doctoral, Université Grenoble Alpes. Recuperado de: https://tel.archivesouvertes.fr/tel-01690643/document [17/10/2018].

LUDMER, Josefina (2006): “Literaturas postautónomas", Linkillo (cosas mías). Recuperado de: http://linkillo.blogspot.com/2006/12/dicen-que 18.html [17/10/2018].

MARTÍN GIRÁLDEZ, Rubén (2012): Menos joven. Zaragoza, Jekyll \& Jill.

MENÉNDEZ SALMÓN, Ricardo (2018): Homo Lubitz. Barcelona, Seix Barral.

MESA, Sara (2017): Un incendio invisible. Barcelona, Anagrama.

MORA, Vicente Luis (2007a): Circular 07. Las afueras. Córdoba, Berenice.

--- (2007b): La luz nueva. Singularidades en la narrativa española actual. Córdoba, Berenice.

--- (2012): El lectoespectador. Barcelona, Seix Barral.

--- (2015): "Fragmentarismo y fragmentalismo en la narrativa hispánica". Cuadernos Hispanoamericanos 783: 91-103.

MORALES, Cristina (2013): Los combatientes. Barcelona, Caballo de Troya.

MORENO, Lara (2013): Por si se va la luz. Barcelona, Lumen.

NAVAJAS, Gonzalo (2000): "El futuro como estética. La literatura ante el siglo XXI". Salina 14: $195-200$.

OLMOS, Alberto (2014): Alabanza. Barcelona, Mondadori.

ORDOVÁS, Julio José (2017): Paraíso Alto. Barcelona, Anagrama.

PANTEL, Alice (2012): "Mutations contemporaines du roman espagnol: Agustín Fernández Mallo et Vicente Luis Mora". Tesis doctoral, Université Paul-Valéry - Montpellier III. Recuperado de: https://halshs.archives-ouvertes.fr/tel-00938342 [17/10/2018].

RIESTRA, Blanca (2016): Greta en su laberinto. Madrid, Alianza Editorial.

RULFO, Juan (1998): Pedro Páramo. Madrid, Cátedra.

SAUM-PASCUAL, Alexandra (2012): "Mutatis Mutandi: Literatura española del nuevo siglo XXI". Tesis doctoral, University of California, Riverside. Recuperado de: http://escholarship.org/uc/item/7sp5h42q [17/10/2018].

--- (2018): \#Postweb! Crear con la máquina y en la red. Madrid / Frankfurt, Iberoamericana / Vervuert. DOI: https://doi.org/10.31819/9783954877065

SPERANZA, Graciela (2000): Manuel Puig: Después del fin de la literatura. Buenos Aires, Grupo Editorial Norma.

TOPUZIÁN, Marcelo (2013): "El fin de la literatura. Un ejercicio de teoría literaria comparada". Castilla 4: 298-349. 
VILAS, Manuel (2011): Los inmortales. Madrid, Alfaguara.

(C) Adolfo R. Posada

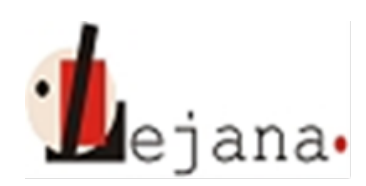

http://ojs.elte.hu/index.php/lejana

Universidad Eötvös Loránd, Departamento de Español, 1088 Budapest, Múzeum krt. 4/C 